\title{
UPLC-DAD/Q-TOF-MS Based Ingredients Identification and Vasorelaxant Effect of Ethanol Extract of Jasmine Flower
}

\author{
Yongqiang Yin, ${ }^{1}$ Xuhui Ying, ${ }^{2}$ Hairong Luan, ${ }^{3}$ Zhenying Zhao, ${ }^{4}$ Jianshi Lou, ${ }^{1}$ \\ Deli Wang, ${ }^{3}$ Hailin $\mathrm{Li}^{3}{ }^{3}$ and Hong $\mathrm{Wu}^{\mathrm{1}, 3}$ \\ ${ }^{1}$ Department of Pharmacology, Tianjin Medical University, Tianjin 300070, China \\ ${ }^{2}$ College of Pharmacy, Nankai University, Tianjin 300071, China \\ ${ }^{3}$ Center of Functional Experiment Teaching and Key Laboratory of Cancer Prevention Research, Mudanjiang Medical University, \\ Mudanjiang, Heilongjiang 157011, China \\ ${ }^{4}$ Department of Pharmacy, Tianjin Union Medical Center, Tianjin 300121, China
}

Correspondence should be addressed to Hong Wu; wuhongmedu@126.com

Received 8 January 2014; Revised 29 March 2014; Accepted 6 April 2014; Published 21 May 2014

Academic Editor: Mohd Roslan Sulaiman

Copyright (C) 2014 Yongqiang Yin et al. This is an open access article distributed under the Creative Commons Attribution License, which permits unrestricted use, distribution, and reproduction in any medium, provided the original work is properly cited.

Chinese people commonly make jasmine tea for recreation and health care. Actually, its medicinal value needs more exploration. In this study, vasorelaxant effect of ethanol extract of jasmine flower (EEJ) on isolated rat thoracic aorta rings was investigated and $\left[\mathrm{Ca}^{2+}\right]$ was determined in vascular smooth muscle cells by laser scanning confocal microscope (LSCM). The result of aorta rings showed that EEJ could cause concentration-dependent relaxation of endothelium-intact rings precontracted with phenylephrine or $\mathrm{KCl}$ which was attenuated after preincubation of the rings with L-NAME and three different $\mathrm{K}^{+}$channel inhibitors; however, indomethacin and glibenclamide did not affect the vasodilatation of EEJ. In addition, EEJ could inhibit contraction induced by PE on endothelium-denuded rings in $\mathrm{Ca}^{2+}$-free medium as well as by accumulation of $\mathrm{Ca}^{2+}$ in $\mathrm{Ca}^{2+}$-free medium with high $\mathrm{K}^{+}$. LSCM also showed that EEJ could lower the elevated level of $\left[\mathrm{Ca}^{2+}\right]$ induced by $\mathrm{KCl}$. These indicate that the vasodilation of EEJ is in part related to causing the release of nitric oxide, activation of $\mathrm{K}^{+}$channels, inhibition of influx of excalcium, and release of calcium from sarcoplasmic reticulum. A total of 20 main ingredients, were identified in EEJ by UPLC-DAD/Q-TOF-MS. The vasodilation activity should be attributed to the high content of flavonoid glycosides and iridoid glycosides found in EEJ.

\section{Introduction}

Jasmine (Jasminum sambac (L.)), one of perennial evergreen shrub, is mostly distributed in tropical Asia and temperate regions in Europe and Africa. Their roots, leaves, and flowers have medicinal values [1]. Its flower is widely used in tea industries nowadays and it has been utilized as traditional medicines in early China to treat a variety of diseases such as diarrhea and fever, which was recorded in one of the famous traditional Chinese medical classics called "Compendium of Materia Medica” (Bencao Gangmu, AD 1578). There have few literatures reported on the ingredients in their roots and flowers by column chromatography, gas chromatography (GC), and thin-layer chromatography (TLC) [2-7]; however, there still have no systemic analysis of the ingredients in its flower by liquid chromatography coupled with mass spectrometry (LC-MS) method. Though jasmine has been used as traditional medicine for a long time, there has been rare research about its pharmacological effects mainly on sedative-hypnotic and anesthesia-analgesic action of its root extracts and fewer on cardiovascular pharmacological effects $[8,9]$, and very few research reported on the vasodilation effect of jasmine flower which mainly focused on the action of causing the release of nitric oxide by EEJ [10]. Our previous study reported vasodilation effect of aqueous extract of jasmine [11]. Continuously, in this study, UPLC-DAD/Q-TOFMS technology was adopted to identify the main ingredients in the ethanol extract of jasmine flower in order to explore its mechanism of vasorelaxant effect for better clinical use, apart from the action of causing the release of nitric oxide, 
activating $\mathrm{K}^{+}$channels, and decreasing intracellular calcium level which were investigated using isolated rat thoracic aorta rings and laser scanning confocal microscope (LSCM).

\section{Materials and Methods}

2.1. Chemicals and Reagents. LC-MS-grade acetonitrile and HPLC-grade methanol were purchased from Fisher Scientific (Fair Lawn, NJ, USA). Formic acid (98\%) was purchased from Acros Organics (Geel, Belgium). $\mathrm{N}^{\mathrm{G}}$-nitro-L-arginine methyl ester (L-NAME), indomethacin (Indo), 4-aminopyrimide, (4-AP), tetraethylammonium (TEA), glibenclamide (GLi), $\mathrm{BaCl}_{2}$, phenylephrine (PE), carbacholine $(\mathrm{CCH}), \mathrm{EGTA}$, DMSO, and Fluo-3/AM were purchased from Invitrogen (CA, USA). Water was purified with a Milli-Q system (Millipore, Bedford, USA). Other reagents were of analytical grade.

2.2. Preparation of Crude Sample of EEJ. Dried jasmine flower was purchased from Chinese herb market, Anguo, Hebei, China, and authenticated by Dr. Chunfeng Xie of Nanakai University. $50 \mathrm{~g}$ jasmine flower was refluxed twice with $80 \%$ ethanol $(500 \mathrm{~mL})$ for $2 \mathrm{~h}$. The filtered supernatants were combined and condensed under decompression at $30^{\circ} \mathrm{C}$. The residue was dissolved in water and extracted with petroleum ether for four times. Water-soluble portion was condensed under decompression to get the crude sample $(5.9 \mathrm{~g})$. And then it was prepared in water at concentration of $50 \mathrm{~g} / \mathrm{L}$ for further use. $1 \mathrm{~mL}$ of solution was taken and diluted to $10 \mathrm{~mL}$ with water, followed by filtration with a $0.22 \mu \mathrm{m}$ filter before UPLC-DAD/Q-TOF-MS analysis.

2.3. UPLC-DAD/Q-TOF-MS Analysis. EEJ solution was analyzed by a Waters Acquity UPLC chromatographic system (Waters Corp., Milford, USA) coupled with a Waters QTOF premier instrument with electrospray ionization system (Waters MS Technologies, Manchester, UK). Chromatographic separation was carried out on Waters Acquity UPLC BEH C18 column $(2.1 \mathrm{~mm} \times 100 \mathrm{~mm}, 1.7 \mu \mathrm{m})$ and the temperature of the column oven was maintained at $35^{\circ} \mathrm{C}$. The mobile phase system including acetonitrile (A) and water with $0.1 \%$ formic acid (B) was performed by gradient elution as follows: $2-20 \%$ A from $0-10 \mathrm{~min}, 20-35 \%$ A from $10-$ $15 \mathrm{~min}$, and $35-100 \%$ A from $15-17 \mathrm{~min}$. The sample was injected $2 \mu \mathrm{L}$ for analysis. UV spectra were recorded from 190 to $400 \mathrm{~nm}$. The flow rate was set at $0.4 \mathrm{~mL} / \mathrm{min}$. The ESIMS spectra were acquired in both negative and positive ion modes and the mass range was set from $\mathrm{m} / z 100$ to 1500 . The capillary voltage was set to $2.5 \mathrm{kV}$ for negative and $3.0 \mathrm{kV}$ for positive ion mode. The sample cone voltage was set at $30 \mathrm{~V}$. The desolvation gas flow was set to $600 \mathrm{~L} / \mathrm{h}$ at a desolvation temperature of $350^{\circ} \mathrm{C}$. The cone gas was set to $50 \mathrm{~L} / \mathrm{h}$ and the source temperature was $110^{\circ} \mathrm{C}$. The collision energy of dissociation was set at $35 \mathrm{eV}$ in MS/MS analysis.

2.4. Animals. Male Wistar rats (250-300 g) were purchased from the Centre of Laboratory Animals, Harbin Medical University, China. All animals were kept in an animal room with a temperature of $23 \pm 2^{\circ} \mathrm{C}$, a humidity of $60 \pm 5 \%$, and a $12 \mathrm{~h}$ dark to light cycle. They had free access to food and water. The animal facilities and protocols were approved by the Institutional Animal Care and Use Committee, Harbin Medical University. All procedures were in accordance with the National Institute of Heath's guidelines regarding the principles of animal care (2004). The experiment animals were housed under the above conditions for a 2 -week acclimation period.

2.5. Preparation of Rat Aortic Rings. Rat aortic rings were prepared according to $[12,13]$. The segment of thoracic aorta was carefully exposed after thoracotomy, dissected free, and quickly placed in chilled $\left(4^{\circ} \mathrm{C}\right)$ Kreb's-Henseleit (K$\mathrm{H})$ solution. Segments were trimmed of adherent adipose and connective tissues and cut into rings in length of 3$4 \mathrm{~mm}$. Endothelium was removed mechanically by gently rubbing the intimal surface of the vessel with fine tipped forceps. The aorta rings were incubated in HV-4 vascular ring perfusion system (Chengdu Taimeng, China) containing $37^{\circ} \mathrm{C} \mathrm{K}-\mathrm{H}$ solution continuously bubbled with $95 \% \mathrm{O}_{2}$ and $5 \%$ $\mathrm{CO}_{2}$ and were mounted horizontally on two stainless steel hooks. One of the hooks was fixed to the bottom, and the other was connected to a force displacement transducer that was connected to BL-420 biological function experimental system (Chengdu Taimeng, China) and JH-2 muscle tension transducer (Beijing Institute of Space Medico-Engineering). Before starting, $0.5 \mathrm{~g}$ resting tension was given to balance for $40 \mathrm{~min}$, and then the resting tension was adjusted to $1.5 \mathrm{~g}$, reequilibrating for $40 \mathrm{~min}$. Buffer was changed every $20 \mathrm{~min}$ to prevent the accumulation of metabolites. Maximum contraction amplitude induced by $\mathrm{PE}(10 \mu \mathrm{M})$ was considered as $100 \%$, and the ratio of vascular contraction amplitude to chemicals and max amplitude reflected the changes of vascular tonus.

2.6. Effect of EEJ on PE or KCl Precontracted EndotheliumIntact Thoracic Aorta Rings. The vascular rings with endothelium were precontracted with $\mathrm{PE}(10 \mu \mathrm{M})$ or $\mathrm{KCl}(60 \mathrm{mM})$ till reaching a contraction plateau and then treated with EEJ $(0.125,0.25,0.5,1$, and $2 \mathrm{~g} / \mathrm{L})$ for $5 \mathrm{~min}$. The effect of each concentration was allowed to reach a steady level before the addition of the next dose.

2.7. Influence of L-NAME or Indo on Vasodilatation Effect of $E E J$. Aortic rings with endothelium were preincubated with L-NAME $(3 \mathrm{mM})$ or Indo $(10 \mu \mathrm{M})$ at $37^{\circ} \mathrm{C}$ for $10 \mathrm{~min}$, followed by precontraction with $\mathrm{PE}(10 \mu \mathrm{M})$ till reaching a contraction plateau, and then treated with EEJ $(0.125,0.25,0.5,1,2 \mathrm{~g} / \mathrm{L})$ for 5 min cumulatively.

2.8. Influence of Potassium Channel Blockers on Vasodilatation Effect of EEJ. Aortic rings with endothelium were preincubated with potassium channel blockers $\mathrm{BaCl}_{2}$ (1 mM), 4-AP $(5 \mathrm{mM})$, TEA $(1 \mathrm{mM})$, and $\mathrm{GLi}(10 \mu \mathrm{mM})$, respectively, at $37^{\circ} \mathrm{C}$ for $10 \mathrm{~min}$, followed by precontraction with $\mathrm{PE}(10 \mu \mathrm{M})$ till reaching maximum contraction, and then treated with EEJ $(0.125,0.25,0.5,1$, and $2 \mathrm{~g} / \mathrm{L})$ for 5 min cumulatively. 


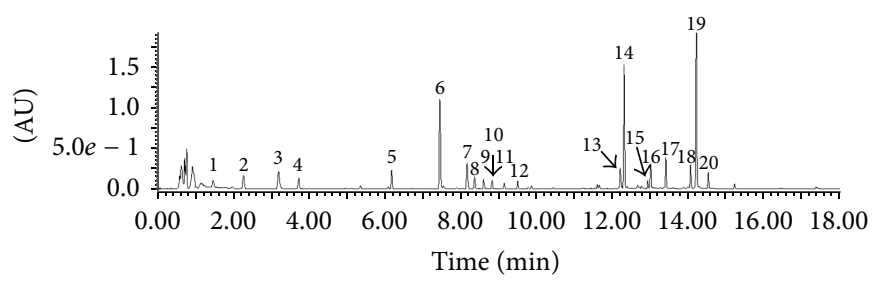

(a)

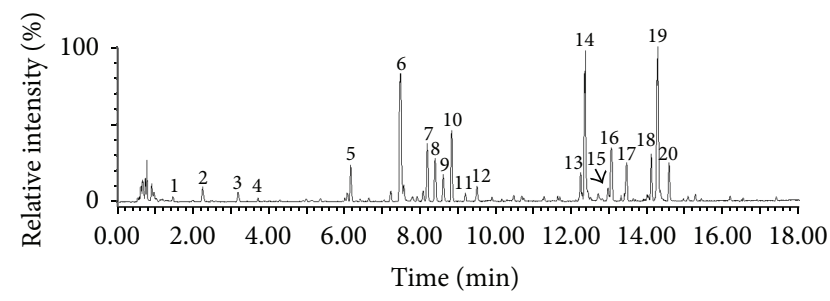

(b)

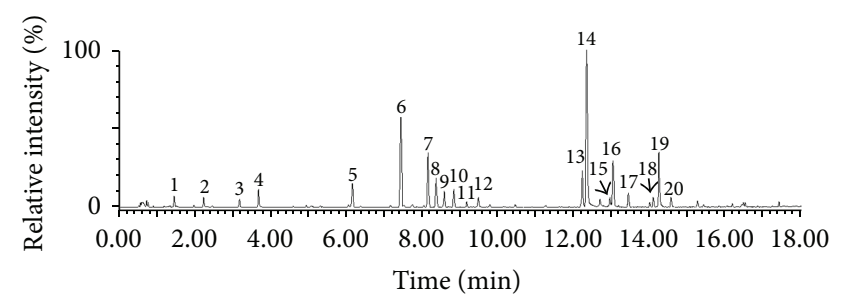

(c)

FIGURE 1: Chromatograms of EEJ analyzed by UPLC-DAD/Q-TOF-MS. (a) UV chromatogram of EEJ (scanned from $190 \mathrm{~nm}$ to $400 \mathrm{~nm}$ ). (b) TIC chromatogram of EEJ in positive ion mode. (c) TIC chromatogram of EEJ in negative ion mode. Peak numbers are consistent with those shown in Table 1.

2.9. Influence of EEJ on Dose-Response Curve of $\mathrm{CaCl}_{2}$. Aortic rings without endothelium were preincubated in $\mathrm{Ca}^{2+}$-free $\mathrm{K}$ $\mathrm{H}$ solution (containing $100 \mu \mathrm{M}$ EGTA) for $30 \mathrm{~min}$ (changing $\mathrm{K}-\mathrm{H}$ buffer at $10 \mathrm{~min}$ intervals), then add $60 \mathrm{mM} \mathrm{KCl}$ for $10 \mathrm{~min}$, followed by addition of five different concentrations of $\mathrm{CaCl}_{2}(0.5,1,2,4$, and $8 \mathrm{mM})$ for 10 min cumulatively. The EEJ group was incubated with EEJ $(1 \mathrm{~g} / \mathrm{L})$ for $30 \mathrm{~min}$ before adding $\mathrm{CaCl}_{2}$.

2.10. Influence of EEJ on PE Induced Vasoconstriction in $\mathrm{Ca}^{2+}$-Free K-H Solution. Aortic rings without endothelium were preincubated in $\mathrm{Ca}^{2+}$-free $\mathrm{K}-\mathrm{H}$ solution (containing $100 \mu \mathrm{mol} / \mathrm{L}$ EGTA) for $30 \mathrm{~min}$ and then precontracted with $\mathrm{PE}(10 \mu \mathrm{M})$ for $10 \mathrm{~min}$, recording max contraction amplitude and calculating tension difference. After several washings and reequilibration, the aortic rings were incubated with $\mathrm{Ca}^{2+}$ free $\mathrm{K}-\mathrm{H}$ solution for $30 \mathrm{~min}$, followed by addition of EEJ $(1 \mathrm{~g} / \mathrm{L})$ for $10 \mathrm{~min}$, and then treated with PE $(10 \mu \mathrm{M})$ for $10 \mathrm{~min}$, recording max contraction amplitude and calculating tension difference. Compare the two tension differences to investigate the effect of EEJ on PE-induced vasoconstriction in $\mathrm{Ca}^{2+}$-free environment.

2.11. Acute Isolation of Rat Thoracic Aortic Smooth Muscle Cells and Detection Intracellular Calcium with Laser Confocal. Acute isolation of rat thoracic aortic smooth muscle was performed as described [14]. Cells were loaded with Fluo$3 / \mathrm{AM}(20 \mu \mathrm{M})$, incubated in $37^{\circ} \mathrm{C}$ water bath for $45 \mathrm{~min}$, removed the loading buffer, and washed with normal Hank's. Loaded cells were treated with $1 \mathrm{~g} / \mathrm{L}$ of EEJ, $2 \mathrm{~g} / \mathrm{L}$ of EEJ, and $10 \mu \mathrm{M}$ of verapamil for $10 \mathrm{~min}$, respectively, and then adding $\mathrm{KCl}(30 \mathrm{mM})$. Confocal scanned real time intracellular $\mathrm{Ca}^{2+}$ concentration $\left(\left[\mathrm{Ca}^{2+}\right]_{i}\right)$ was performed at $488 / 525 \mathrm{~nm}$ (Ex/Em) with FV-300 laser scanning confocal microscope (Olympus, Japan). The data are presented as a ratio of $F_{\max } / F_{0}$.
2.12. Statistical Analysis. Data were presented as mean \pm SD. The significance in mean values was analyzed by $t$-test for 2 groups and by analysis of variance (ANOVA) with least squares difference post-hoc test for more than 2 groups. A $P$ value of less than 0.05 was regarded as a statistically significant difference.

\section{Results}

3.1. Identification Result of EEJ by UPLC-DAD/Q-TOF-MS. The typical UV chromatogram (full wavelength scan chromatogram from 200 to $400 \mathrm{~nm}$ ) and total ion current (TIC) chromatograms (positive ion mode and negative ion mode) of EEJ are shown in Figure 1. The accurate mass ions obtained from positive and negative TIC chromatograms and the fragment ions obtained from MS/MS model are summarized in Table 1 . In total, 20 compounds in EEJ were tentatively identified, most of which belonged to flavonoid glycoside, iridoid glycosides, and quercetin-3-O-(2,6- $\alpha$-Lrhamnopyranosyl- $\beta$-D-glucopyranoside) (peak 6), molihuaside A (peak 14), and sambacoside A (peak 19) with relatively high content.

3.2. Effect of EEJ on PE or KCl Precontracted EndotheliumIntact Thoracic Aorta Rings. As shown in Figure 2(a), EEJ caused vasodilation of the endothelium-intact thoracic aorta ring preconstricted with $\mathrm{PE}$ in a concentration-dependent manner. The max vasodilatation amplitude was $103 \pm 3.6 \%$ and $96 \pm 3.1 \%$ for $\mathrm{KCl}$ and $\mathrm{PE}$ precontraction, respectively.

3.3. Influence of L-NAME or Indo on Vasodilatation Effect of EEJ. As shown in Figure 2(b), there has no significant difference $(P>0.05)$ on the vasodilation effect of EEJ on $\mathrm{PE}$ precontracted aortic rings with endothelium in presence or absence of Indo, a cyclooxygenase inhibitor. However, 


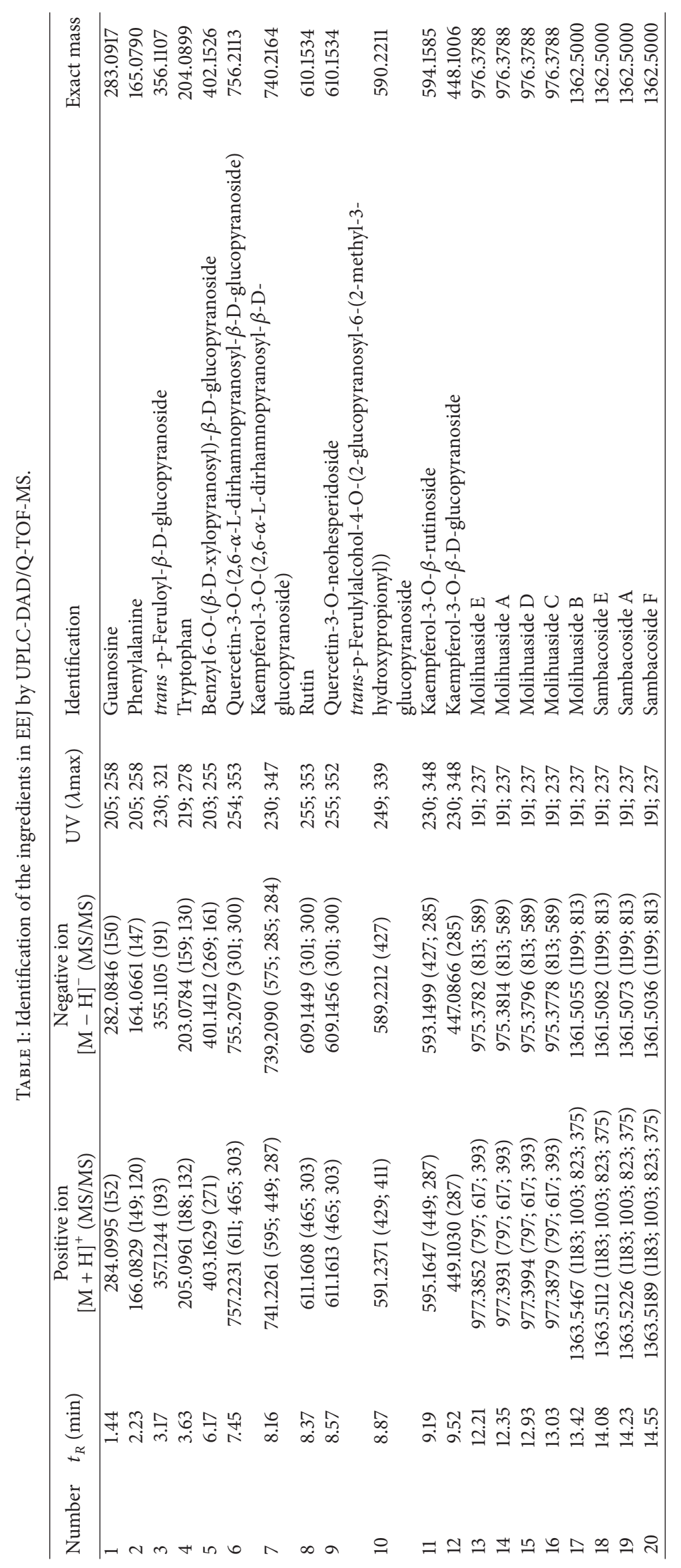




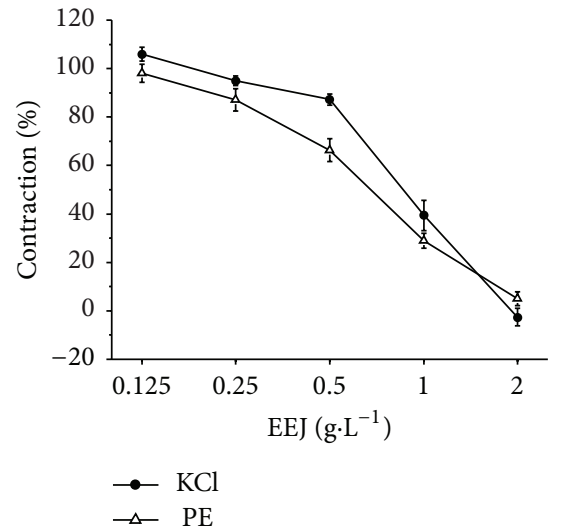

(a)

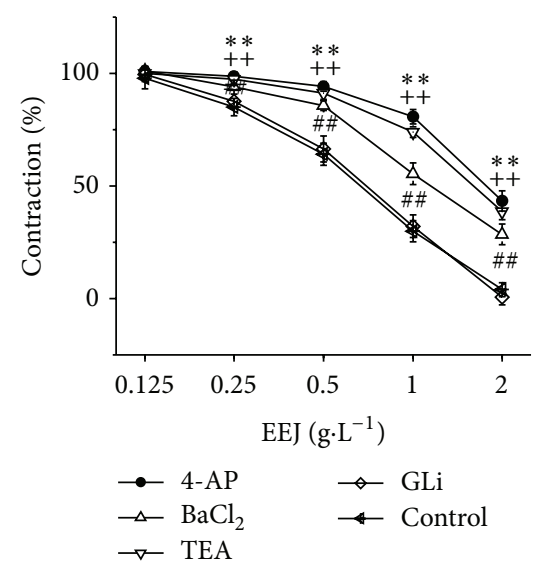

(c)

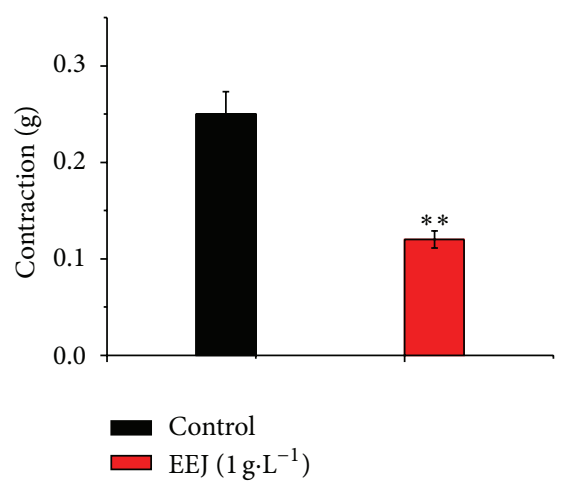

(e)

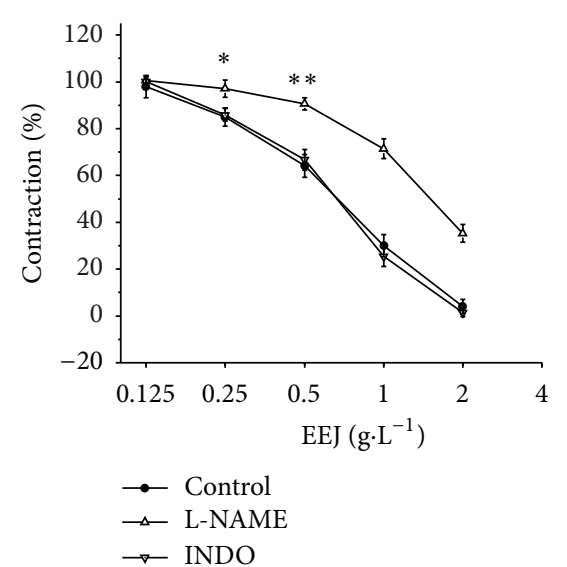

(b)

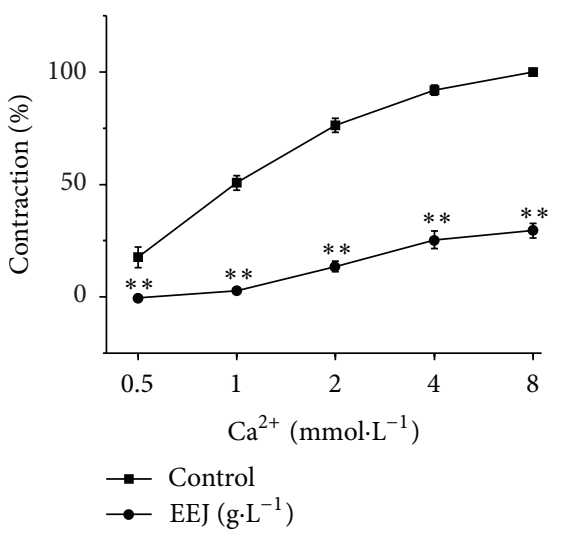

(d)

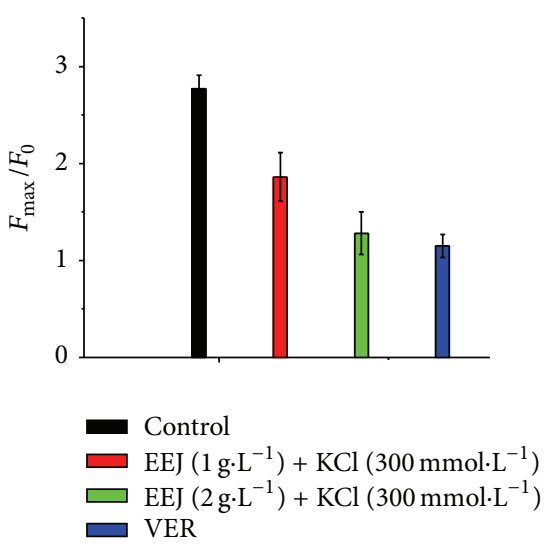

(f)

FIGURE 2: Vasorelaxant effect of EEJ. Data are expressed as mean \pm SD $(n=8)$. (a) Cumulative concentration response for EEJ $(0.125,0.25,0.5$, 1 , and $2 \mathrm{~g} / \mathrm{L})$ on $\mathrm{PE}(10 \mu \mathrm{M})$ or $\mathrm{KCl}(60 \mathrm{mM})$ precontracted endothelium-intact thoracic aorta rings. Maximum contraction amplitude induced by PE $(10 \mu \mathrm{M})$ is considered as $100 \%$. (b) Effects of L-NAME $(3 \mathrm{mM})$ and Indo $(10 \mu \mathrm{M})$ on EEJ induced relaxation in the endothelium-intact aorta rings precontracted with $\mathrm{PE}(10 \mu \mathrm{M}) .{ }^{*} \mathrm{P}<0.05,{ }^{* *} \mathrm{P}<0.01$ compared with control group. (c) Effects of $4-\mathrm{AP}(5 \mathrm{mM}), \mathrm{BaCl}_{2}(1 \mathrm{mM})$, TEA $(1 \mathrm{mM})$, and GLi $(10 \mu \mathrm{M})$ on EEJ induced relaxation in the endothelium-intact aorta rings precontracted with $\mathrm{PE}(10 \mu \mathrm{M}) .{ }^{* *} \mathrm{P}<0.01$ compared 4-AP treating group with control group; ${ }^{++} P<0.01$ compared TEA treating group with control group; ${ }^{\# \#} P<0.01$ compared $\mathrm{BaCl}_{2}$ treating group with control group. (d) Effects of EEJ $(1 \mathrm{~g} / \mathrm{L})$ on the cumulative concentration response for $\mathrm{CaCl}_{2}(0.5 \mathrm{mM}-8 \mathrm{mM})$ in high $\mathrm{K}^{+}$ $(60 \mathrm{mM})-\mathrm{Ca}^{2+}$-free depolarizing solution. ${ }^{* *} P<0.01$ compared with control group. (e) Effect of EEJ $(1 \mathrm{~g} / \mathrm{L})$ on the PE $(10 \mu \mathrm{M})$ precontracted endothelium-denuded aortic rings in the $\mathrm{Ca}^{2+}$-free $\mathrm{K}-\mathrm{H}$ solution. ${ }^{* *} \mathrm{P}<0.01$ compared with the $\mathrm{Ca}^{2+}$-containing group. (f) Influence of EEJ $(1 \mathrm{~g} / \mathrm{L}, 2 \mathrm{~g} / \mathrm{L})$ on the increase of $\left[\mathrm{Ca}^{2+}\right]_{i}$ in ASMCs induced by $\mathrm{KCl}(30 \mathrm{mM})$. Verapamil $(\mathrm{VER}, 10 \mu \mathrm{M})$ was applied as the positive inhibition control group. ${ }^{* *} P<0.01 \mathrm{EEJ}(1 \mathrm{~g} / \mathrm{L})$ treating group compared with the control group; ${ }^{\# \#} P<0.01 \mathrm{EEJ}(2 \mathrm{~g} / \mathrm{L})$ treating group compared with the control group; ${ }^{++} P<0.01$ verapamil treating group compared with the control group. 
the vasodilation effect of EEJ on PE precontracted aortic rings with endothelium was significantly decreased after preincubation of the aortic rings with L-NAME, a $\mathrm{NO}$ synthase inhibitor. The max relaxation amplitude was $65.3 \pm$ $3.5 \%$, a significant difference $(P<0.05)$ compared to the control group.

3.4. Influence of Potassium Channel Blockers on Vasodilatation Effect of EEJ. Figure 2(c) shows that voltage-sensitive $\mathrm{K}^{+}$ channels $\left(\mathrm{K}_{\mathrm{v}}\right)$ inhibitor 4-AP, inwardly rectifying $\mathrm{K}^{+}$channels $\left(\mathrm{K}_{\mathrm{IR}}\right)$ inhibitor $\mathrm{BaCl}_{2}$, and $\mathrm{Ca}^{2+}$-activated $\mathrm{K}^{+}$channel $\left(\mathrm{K}_{\mathrm{Ca}}\right)$ inhibitor TEA significantly attenuate vasodilation effect of EEJ on PE precontracted aortic rings, with the max relaxation amplitude of $57 \pm 4.5 \%, 78 \pm 4.6 \%$, and $61 \pm 3.6 \%$, respectively, a significant difference compared with the control group $(P<0.01)$. Nevertheless, there was no significant decrease in the percentage maximum relaxation response of $\mathrm{PE}$ precontracted aortic rings with preincubation of $\mathrm{GLi}$, a $\mathrm{K}_{\mathrm{ATP}}$ nonspecific inhibitor, when compared with PE precontracted aortic rings without preincubation of GLi.

3.5. Influence of EEJ on Dose-Response Curve of $\mathrm{CaCl}_{2}$. Figure 2(d) shows that the dose-response curve of $\mathrm{CaCl}_{2}$ was shifted to right and the contraction was significantly $(P<$ 0.01 ) decreased when the aorta rings were pretreated with EEJ $(1 \mathrm{~g} / \mathrm{L})$ in $\mathrm{Ca}^{2+}$-free $\mathrm{K}-\mathrm{H}$ solution (containing $100 \mu \mathrm{M}$ EGTA).

3.6. Influence of EEJ on PE Induced Vasoconstriction in $\mathrm{Ca}^{2+}$ Free K-H Solution. As shown in Figure 2(e), EEJ significantly inhibited $\mathrm{PE}$ induced vasoconstriction in $\mathrm{Ca}^{2+}$-free $\mathrm{K}-\mathrm{H}$ solution, and the max tension was reduced by $0.13 \pm 0.014 \mathrm{~g}$, a significant difference compared with the control group $(P<$ $0.01)$.

3.7. Influence of EEJ on Cytoplasm $\left[\mathrm{Ca}^{2+}\right]_{i}$ of ASMC. After loaded with Fluo-3/AM, ASMCs were scanned with confocal. As shown in Figure 2(f), EEJ inhibited KCl-induced $\left[\mathrm{Ca}^{2+}\right]_{i}$ increase in a dose-dependent manner. The $F_{\max } / F_{0}$ of $\left[\mathrm{Ca}^{2+}\right]_{i}$ was at $1.86 \pm 0.25$ when $1 \mathrm{~g} / \mathrm{L}$ of EEJ was added, while the $F_{\max } / F_{0}$ of $\left[\mathrm{Ca}^{2+}\right]_{i}$ was decreased to $1.28 \pm 0.22$ when $2 \mathrm{~g} / \mathrm{L}$ of EEJ was added; both showed significant difference $(P<0.01)$ compared with the control group whose $F_{\max } / F_{0}$ of $\left[\mathrm{Ca}^{2+}\right]_{i}$ was at $2.77 \pm 0.14$.

\section{Discussions}

Jasmine flower is widely used as a tea in the world, especially in East Asia, and it has been traditionally used in ancient China as a medicine treating diarrhea and conjunctivitis. Nevertheless, the ingredients and pharmacological activities of jasmine flower have been rarely reported, especially on its vasodilation effect.

In UPLC-DAD/Q-TOF-MS analysis, the chromatographic conditions for analysis of EEJ were optimized by comparing different mobile phase systems with different gradient elution programs (methanol/water and acetonitrile/water), different water phase additives with different concentrations (formic acid and acetic acid with a concentration of $0.05 \%, 0.1 \%$, and $0.5 \%$, resp.), and different column temperatures (30, 35 , and $40^{\circ} \mathrm{C}$ ). Finally, a rapid analytical method with good separation for most of compounds in EEJ was established.

The accurate mass ions, fragment ions and maximum UV absorptions of peaks 1, 2, and 4 were consistent with previous report [15]. Hence, they were identified as guanosine, phenylalanine, and tryptophan, respectively. Peak 3 showed a positively charged molecular ion $[\mathrm{M}+\mathrm{H}]^{+}$at $\mathrm{m} / z$ 357 and negatively charged molecular ion $[\mathrm{M}-\mathrm{H}]^{-}$at $\mathrm{m} / \mathrm{z}$ 355 indicating a $\mathrm{MW}$ of 356 . It gave major fragment ion by loss of $\mathrm{m} / \mathrm{z} 162$ (glucose- $\mathrm{H}_{2} \mathrm{O}$ ) in both positive and negative ion MS/MS analysis. Additionally, it exhibited a characteristic UV absorption at $320 \mathrm{~nm}$. So it was presumed as trans-p-feruloyl- $\beta$-D-glucopyranoside which had been identified in a medicinal flower [16]. Peak 10 showed a MW of $590 \mathrm{Da}$ deduced from MS results and was tentatively identified as trans-p-ferulylalcohol-4-O-(2-glucopyranosyl6-(2-methyl-3-hydroxypropionyl)) glucopyranoside (FGG) based on the spectra data of trans-p-ferulylalcohol-4-O-(6(2-methyl-3-hydroxypropionyl) glucopyranoside (FG) which showed a MW of 428 Da reported in [17]. Peak 10 had similar characteristic UV absorption at 250 and $340 \mathrm{~nm}$ with FG predicting that peak 10 probably had the same structure skeleton with FG. It could form fragment ions at $\mathrm{m} / z 429$ in positive ion model and $\mathrm{m} / z 427$ in negative ion model by loss of $162 \mathrm{Da}$ corresponding to glucopyranose which means that peak 10 has one glucopyranosyl group more than FG. In addition, peak 10 could also form fragment ions at $\mathrm{m} / \mathrm{z} 411$ in positive ion model by losses of $162 \mathrm{Da}$ (glucose$\mathrm{H}_{2} \mathrm{O}$ ) and cleave off a $\mathrm{H}_{2} \mathrm{O}$ at 2-methyl-3-hydroxypropionyl side chain. Similarly, peak 5 was identified as benzyl 6$\mathrm{O}-(\beta$-D-xylopyranosyl)- $\beta$-D-glucopyranoside which could form a fragment of benzyl-O- $\beta$-D-glucopyranoside, and a compound had been earlier reported in a medicinal flower [16] and food [18], by loss of one xylopyranosyl group.

Peaks 6, 7, 8, 9, 11, and 12 were all flavonoid glycoside taking quercetin or kaempferol as aglycone. They were identified based on their UV and mass spectral data compared to those in the literature $[16,18]$. Normally, these compounds could be losses of glucopyranosyl or/and rhamnopyranosyl groups in the MS/MS analysis. For some compounds with quercetin as aglycone, quercetin-free radical fragment was formed at $\mathrm{m} / z$ 300 in negative ion MS/MS analysis.

Peaks 13, 14, 15, 16, 17, 18, 19, and 20 that were all iridoid glycosides showed same maximum UV absorptions at 191 and $237 \mathrm{~nm}$. They were confirmed by the mass spectral data and contents of them reported earlier in jasmine $[19,20]$. Peaks 13, 14, 15, and 16 were isomers, and they could form fragments at $m / z 797$ and 617 in positive mode by losses of one and two glucopyranoses, respectively. And the fragment of $m / z 393$ was formed by further loss of one molecular iridoid aglycone. They gave the fragments of $m / z 813$ and 589 in negative mode by losses of glucopyranosyl and one molecular iridoid glycoside, respectively. Similarly, peaks 17, 18,19 , and 20 showed the main fragments in positive mode by losses of one or more glucopyranoses or iridoid glycosides while giving the main fragments in negative mode by losses of one glucopyranosyl and one molecular iridoid glycoside. 
Endothelium plays vital roles in aortic ring contraction/relaxation. Vasodilators, such as prostaglandin $\mathrm{I}_{2}\left(\mathrm{PGI}_{2}\right)$ and endothelial derived relaxing factor (EDRF) or nitric oxide (NO), were synthesized and released by vascular endothelium [21,22]. NO is a potent vasodilator synthesized in the endothelium by $\mathrm{NO}$ synthase, and activating $\mathrm{M}_{3}$ cholinergic receptors on endothelial cells can also lead to the release of NO [23]. NO causes vascular relaxation by stimulating guanylate cyclase, increasing intracellular cGMP, and decreasing $\mathrm{Ca}^{2+}$. $\mathrm{PGI}_{2}$ is synthesized by prostacyclin synthase in endothelial cells [24]. As shown in Figure 2(a), EEJ could antagonize $\mathrm{PE}$ or $\mathrm{KCl}$-induced vasoconstriction in a concentration-dependent manner. But this effect could be significantly attenuated by L-NAME, a NO synthase inhibitor, as shown in Figure 2(b), which is consistent with a previous report [10]; however, indole, a prostacyclin synthase inhibitor, did not influence on the vasodilatation of EEJ. It indicates that the vasodilatation effect of EEJ might be related to $\mathrm{M}_{3}$ receptor or L-arginine/NO pathway but not to $\mathrm{PGI}_{2}$ pathway.

Ion channels, such as $\mathrm{K}^{+}$channel and $\mathrm{Ca}^{2+}$ channel, also participate in vascular smooth muscle contraction/relaxation. $\mathrm{K}^{+}$channels play important roles in regulating of VSM contraction and vascular tonus. Activating of $\mathrm{K}^{+}$channels in VSM leads to vasodilation by cellular membrane hyperpolarization and inhibiting the influx of extracellular calcium [25]. There are four types of $\mathrm{K}^{+}$channels in VSM: ATP-sensitive $\mathrm{K}^{+}$channels $\left(\mathrm{K}_{\mathrm{ATP}}\right), \mathrm{Ca}^{2+}$ activated $\mathrm{K}^{+}$channels $\left(\mathrm{K}_{\mathrm{ca}}\right)$, voltage-sensitive $\mathrm{K}^{+}$channels $(\mathrm{Kv})$, and inward rectifier-type $\mathrm{K}^{+}$channels $\left(\mathrm{K}_{\mathrm{IR}}\right)$. TEA, 4-AP, and $\mathrm{BaCl}_{2}$ could inhibit $\mathrm{Kca}, \mathrm{Kv}$, and $\mathrm{K}_{\mathrm{IR}}$, respectively [26]. As shown in Figure 2(c), the vasodilation effect of EEJ was partially inhibited when the vascular rings were preincubated with TEA, 4-AP, or $\mathrm{BaCl}_{2}$ before treating with EEJ, indicating that the vasodilatation of EEJ is associated with several $\mathrm{K}^{+}$channels. $\mathrm{K}_{\mathrm{Ca}}, \mathrm{K}_{\mathrm{v}}$, and $\mathrm{K}_{\mathrm{IR}}$ might participate in EEJ vasodilatation, but not $\mathrm{K}_{\mathrm{ATP}}$.

There are two types of $\mathrm{Ca}^{2+}$ channels in VSM cell membrane [27], including voltage dependent calcium channel (VDCC) and receptor operated calcium channel (ROCC). VDCC is regulated voltage-dependently by membrane potential. ROCC is coupled with membrane receptors. Specific ROCC receptor agonists, such as PE, can bind the receptor and activate ROCC, which prompt the release of intracellular $\mathrm{Ca}^{2+}$ from sarcoplasmic reticulum (SR) and influx of extracellular $\mathrm{Ca}^{2+}$, leading to vasoconstriction [28]. PE can also activate $\alpha 1$ receptors in vessels, promoting the release of intracellular $\mathrm{Ca}^{2+}$ from SR. Both pathways lead to the elevation of intracellular $\mathrm{Ca}^{2+}$ and contraction of VSM regulated by calmodulin. High level of extracellular $\mathrm{K}^{+}$ predisposes that the VDCC is activated by depolarizing membrane, leading to influx of extracellular $\mathrm{Ca}^{2+}$ and contraction of vessel [29]. As seen from Figure 2(d), EEJ attenuated the vasoconstriction to cumulative calcium in high potassium medium without $\mathrm{Ca}^{2+}$, suggesting that the vasodilatation effect of EEJ is related to inhibiting the influx of extracellular $\mathrm{Ca}^{2+}$ mediated by VDCC. In $\mathrm{Ca}^{2+}$-free buffer, PE could cause vasoconstriction by inducing the release of $\mathrm{SR} \mathrm{Ca}^{2+}$, which was significantly attenuated by EEJ, as shown in Figure 2(e). The results indicated that inhibiting release of $\mathrm{Ca}^{2+}$ from SR was involved in vasodilatation of EEJ, as for mediated by ROCC or $\alpha_{1}$ receptor pathway would be under further investigation $[30,31]$.

The increased concentration of intracellular $\mathrm{Ca}^{2+}$ directly leads to smooth muscle contraction. EEJ generally relaxed aorta rings precontracted with $\mathrm{PE}$ or $\mathrm{KCl}$, providing evidence that EEJ affected intracellular $\mathrm{Ca}^{2+}$. The confocal data in Figure 2(f) showed that the elevation of intracellular $\mathrm{Ca}^{2+}$ induced by $\mathrm{KCl}$ could be assuaged by EEJ in a concentrationdependent manner, indicating that vasodilatation effect of EEJ is related to decrease of intracellular $\mathrm{Ca}^{2+}$. This result was consistent with vascular ring testing.

To our knowledge, how chemicals affect aorta rings mainly lies in four mechanisms, endothelium dependent, $\mathrm{K}^{+}$ channel related, $\mathrm{Ca}^{2+}$ channel, and receptor dependent. In this study, we found that EEJ mechanisms of vasorelaxant effect at least partly lie in causing the release of nitric oxide, activating $\mathrm{K}^{+}$channels, and decreasing intracellular calcium level. It is known that, the endothelium integrity of hypertension patients varies. In our study, we found that, besides NO release pathway, EEJ also had effects on $\mathrm{K}^{+}$ channel and $\mathrm{Ca}^{2+}$ channel, indicating that EEJ exhibits its vasorelaxant role in multimechanism, which is of clinical significance.

According to our LC-MS result, the main ingredients in EEJ are flavonoid glycosides and iridoid glycosides. It has been reported that the vasorelaxant property of most plant extracts is related to flavonoids [32-36]. In addition, there have several reports on the vasorelaxant effects of iridoid glycosides as well [37]. Hence, the vasodilation activity of EEJ should be attributed to flavonoid glycosides and iridoid glycosides found in EEJ, especially quercetin-3-O-(2,6- $\alpha$-Ldirhamnopyranosyl- $\beta$-D-glucopyranoside), molihuaside $A$, and sambacoside $\mathrm{A}$ which are the relatively high content of flavonoid glycosides and iridoid glycosides identified in EEJ. This study provides useful information for better application of jasmine flower in traditional medicines and tea industries. Nevertheless, further studies are necessary to clearly elucidate the specific ingredients which responsible for such effects and further investigate the mechanism of vasodilation effects of EEJ on molecular level, as well as in vivo study being potentially affected with neural or humor factors.

\section{Conclusion}

In this study, we have a preliminary understanding of the vasodilation effects and potential mechanism of EEJ and find that EEJ has a concentration-dependent relaxation in rat aorta rings by stimulating nitric oxide release, activating multiple potassium channels on VSM, inhibiting influx of extracellular $\mathrm{Ca}^{2+}$, and preventing the release of $\mathrm{Ca}^{2+}$ from $\mathrm{SR}$. The vasodilation activity of EEJ should be attributed to the high content of flavonoid glycosides and iridoid glycosides found in EEJ. 


\section{Conflict of Interests}

The authors declare that they have no conflict of interests.

\section{Authors' Contribution}

Yongqiang Yin, Xuhui Ying, and Hairong Luan are cofirst authors and contributed equally to this work.

\section{Acknowledgments}

This study was financially supported by grants from Traditional Chinese Medicine Research Fund of Heilongjiang Province (ZHY12-W051), Chinese Postdoctoral Fund (20080440687), and National Natural Science Foundation of China (81373410).

\section{References}

[1] H. Liu, W. Ni, M. Yuan, and C. Chen, "The chemical constituents of Jasminum sambac," Acta Botanica Yunnanica, vol. 26, no. 6, pp. 687-690, 2004.

[2] B. Somanadhan, U. W. Smitt, V. George et al., "Angiotensin Converting Enzyme (ACE) inhibitors from Jasminum azoricum and Jasminum grandiflorum," Planta Medica, vol. 64, no. 3, pp. 246-250, 1998.

[3] J. Inagaki, N. Watanabe, J. H. Moon et al., "Glycosidic aroma precursors of 2-phenylethyl and benzyl alcohols from Jasminum sambac flowers," Bioscience, Biotechnology, and Biochemistry, vol. 59, no. 4, pp. 738-739, 1995.

[4] Z.-F. Zhang, B.-L. Bian, J. Yang, and X.-F. Tian, "Studies on chemical constitutents in roots of Jasminum sambac," China Journal of Chinese Materia Medica, vol. 29, no. 3, pp. 237-239, 2004.

[5] A. E. Edris, R. Chizzola, and C. Franz, "Isolation and characterization of the volatile aroma compounds from the concrete headspace and the absolute of Jasminum sambac (L.) Ait. (Oleaceae) flowers grown in Egypt," European Food Research and Technology, vol. 226, no. 3, pp. 621-626, 2008.

[6] L. H. Zeng, M. Hu, Y. M. Yan, Q. Lu, and Y. X. Cheng, "Compounds from the roots of Jasminum sambac," Journal of Asian Natural Products Research, vol. 14, no. 12, pp. 1180-1185, 2012.

[7] V. P. P. S. Pragadheesh, A. Yadav, C. S. Chanotiya, P. K. Rout, and G. C. Uniyal, "Monitoring the emission of volatile organic compounds from flowers of Jasminum sambac using solid-phase micro-extraction fibers and gas chromatography with mass spectrometry detection," Natural Product Communications, vol. 6, no. 9, pp. 1333-1338, 2011.

[8] C. Rath, S. Devi, S. Dash, and R. Mishra, "Antibacterial potential assessment of Jasmine essential oil against E. coli," Indian Journal of Pharmaceutical Sciences, vol. 70, no. 2, pp. 238-241, 2008.

[9] P. T. Chan, W. P. Fong, Y. L. Cheung, Y. Huang, W. K. K. Ho, and Z.-Y. Chen, "Jasmine green tea epicatechins are hypolipidemic in hamsters (Mesocricetus auratus) fed a high fat diet," Journal of Nutrition, vol. 129, no. 6, pp. 1094-1101, 1999.

[10] P. Kunhachan, C. Banchonglikitkul, T. Kajsongkram, A. Khayungarnnawee, and W. Leelamanit, "Chemical composition, toxicity and vasodilatation effect of the flowers extract of Jasminum sambac (L.) Ait. "g. Duke of Tuscany"', Evidencebased Complementary and Alternative Medicine, vol. 2012, Article ID 471312, 7 pages, 2012.

[11] H.-R. Luan, J.-J. Yin, W.-H. Mo, B.-N. Zhang, X.-P. Pang, and Y.-L. Hou, "Vasodilation effect of aqueous extract of jasmine on rat thoracic aorta and its related mechanism," Chinese Pharmaceutical Journal, vol. 45, no. 3, pp. 182-186, 2010.

[12] Z.-Y. Chen, Y.-L. Su, C.-W. Lau, W.-I. Law, and Y. Huang, "Endothelium-dependent contraction and direct relaxation induced by baicalein in rat mesenteric artery," European Journal of Pharmacology, vol. 374, no. 1, pp. 41-47, 1999.

[13] W.-H. Ko, X.-Q. Yao, C.-W. Lau et al., "Vasorelaxant and antiproliferative effects of berberine," European Journal of Pharmacology, vol. 399, no. 2-3, pp. 187-196, 2000.

[14] H. Honda, T. Unemoto, and H. Kogo, "Different mechanisms for testosterone-induced relaxation of aorta between normotensive and spontaneously hypertensive rats," Hypertension, vol. 34, no. 6, pp. 1232-1236, 1999.

[15] X. H. Ying, J. F. Ma, Q. L. Liang, Y. M. Wang, G. Bai, and G. A. Luo, "Identification and analysis of the constituents in an aqueous extract of tricholoma matsutake by HPLC coupled with diode array detection/electrospray ionization mass spectrometry," Journal of Food Science, vol. 78, no. 8, pp. C1173-C1182, 2013.

[16] M. Yoshikawa, S. Sugimoto, S. Nakamura, and H. Matsuda, "Medicinal flowers. XXII structures of chakasaponins V and VI, chakanoside I, and chakaflavonoside a from flower buds of Chinese tea plant (Camellia sinensis)," Chemical and Pharmaceutical Bulletin, vol. 56, no. 9, pp. 1297-1303, 2008.

[17] M. Materska, S. Piacente, A. Stochmal, C. Pizza, W. Oleszekc, and I. Perucka, "Isolation and structure elucidation of flavonoid and phenolic acid glycosides from pericarp of hot pepper fruit Capsicum annuum L," Phytochemistry, vol. 63, no. 8, pp. 893898, 2003.

[18] B. Schwarz and T. Hofmann, "Sensory-guided decomposition of red currant juice (Ribes rubrum) and structure determination of key astringent compounds," Journal of Agricultural and Food Chemistry, vol. 55, no. 4, pp. 1394-1404, 2007.

[19] T. Tanahashi, N. Nagakura, K. Inoue, and H. Inouye, "Sambacosides a, e and $\mathrm{f}$, novel tetrameric iridoid glucosides from Jasminum sambac," Tetrahedron Letters, vol. 29, no. 15, pp. 17931796, 1988.

[20] Z. Y.-J. Zhang, L. Y.-Q. Liu, P. X.-Y. Pu, and Y. C.-R. Yang, "Iridoidal glycosides from Jasminum sambac," Phytochemistry, vol. 38, no. 4, pp. 899-903, 1995.

[21] E. Rosado, A. Rodriguez-Vilarrupla, J. Gracia-Sancho, M. Monclus, J. Bosch, and J. C. Garcia-Pagan, "Interaction between NO and COX pathways modulating hepatic endothelial cells from control and cirrhotic rats," Journal of Cellular and Molecular Medicine, vol. 16, no. 10, pp. 2461-2470, 2012.

[22] A. Pignone, A. Del Rosso, K. B. Brosnihan et al., "Reduced circulating levels of angiotensin-(1-7) in systemic sclerosis: a new pathway in the dysregulation of endothelial-dependent vascular tone control," Annals of the Rheumatic Diseases, vol. 66, no. 10, pp. 1305-1310, 2007.

[23] B. Yang, Pharmacology, People's Medical Publishing House, Beijing, China, 6th edition, 2003.

[24] T. Yao, Physiology, People's Medical Publishing House, Beijing, China, 6th edition, 2003.

[25] S. Seino and T. Miki, "Physiological and pathophysiological roles of ATP-sensitive $\mathrm{K}^{+}$channels," Progress in Biophysics \& Molecular Biology, vol. 81, no. 2, pp. 133-176, 2003. 
[26] W. F. Jackson, "Ion channels and vascular tone," Hypertension, vol. 35, no. 1, pp. 173-178, 2000.

[27] R. Paoletti and S. Govoni, "Classification of calcium antagonists: proposal of the WHO Committee," Pharmacological Research Communications, vol. 19, no. 3, pp. 195-208, 1987.

[28] F. I. Achike, R. Mohamad, M. R. Mustafa, and R. M. Rampal, "Acidosis-induced vasodilation in the rat aorta: the role of voltage- and receptor-operated calcium channels," Medical Science Research, vol. 27, no. 1, pp. 33-34, 1999.

[29] C. M. Rembold, "Regulation of contraction and relaxation in arterial smooth muscle," Hypertension, vol. 20, no. 2, pp. 129137, 1992.

[30] J.-Y. He, W. Zhang, L.-C. He, and Y.-X. Cao, "Imperatorin induces vasodilatation possibly via inhibiting voltage dependent calcium channel and receptor-mediated $\mathrm{Ca}^{2+}$ influx and release," European Journal of Pharmacology, vol. 573, no. 1-3, pp. 170-175, 2007.

[31] X.-C. Fu, M.-W. Wang, S.-P. Li, Y. Zhang, and H.-L. Wang, "Vasodilatation produced by orientin and its mechanism study," Biological \& Pharmaceutical Bulletin, vol. 28, no. 1, pp. 37-41, 2005.

[32] C. Heiss, C. L. Keen, and M. Kelm, "Flavanols and cardiovascular disease prevention," European Heart Journal, vol. 31, no. 21, pp. 2583-2592, 2010.

[33] F. Pérez-Vizcaíno, M. Ibarra, A. L. Cogolludo et al., "Endothelium-independent vasodilator effects of the flavonoid quercetin and its methylated metabolites in rat conductance and resistance arteries," Journal of Pharmacology and Experimental Therapeutics, vol. 302, no. 1, pp. 66-72, 2002.

[34] D. F. Fitzpatrick, S. L. Hirschfield, T. Ricci, P. Jantzen, and R. G. Coffey, "Endothelium-dependent vasorelaxation caused by various plant extracts," Journal of Cardiovascular Pharmacology, vol. 26, no. 1, pp. 90-95, 1995.

[35] C. K. Chen and C. R. Pace-Asciak, "Vasorelaxing activity of resveratrol and quercetin in isolated rat aorta," General Pharmacology, vol. 27, no. 2, pp. 363-366, 1996.

[36] O. L. Woodman and E. C. H. Chan, "Vascular and anti-oxidant actions of flavonols and flavones," Clinical and Experimental Pharmacology and Physiology, vol. 31, no. 11, pp. 786-790, 2004.

[37] T. Iizuka, H. Sakai, H. Moriyama, N. Suto, M. Nagai, and D. Bagchi, "Vasorelaxant effects of forsythide isolated from the leaves of Forsythia viridissima on NE-induced aortal contraction," Phytomedicine, vol. 16, no. 4, pp. 386-390, 2009. 


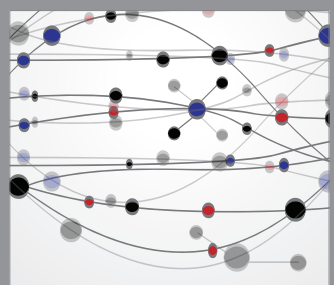

The Scientific World Journal
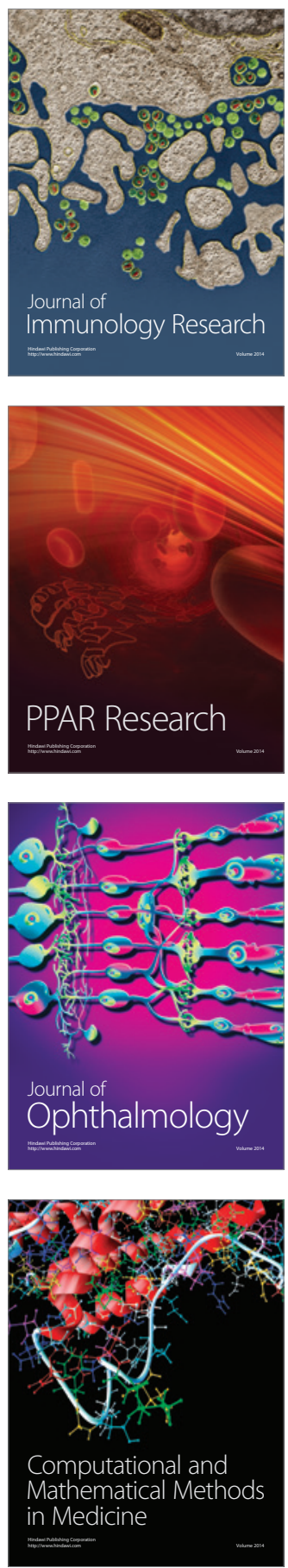

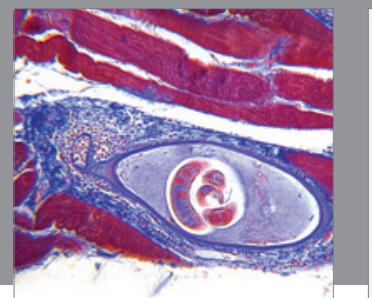

Gastroenterology

Research and Practice
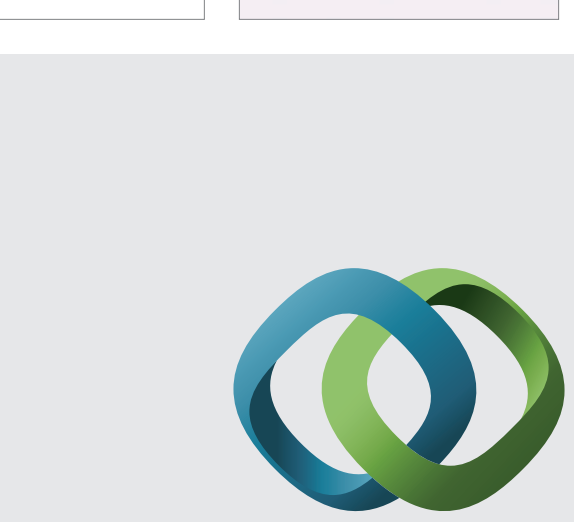

\section{Hindawi}

Submit your manuscripts at

http://www.hindawi.com
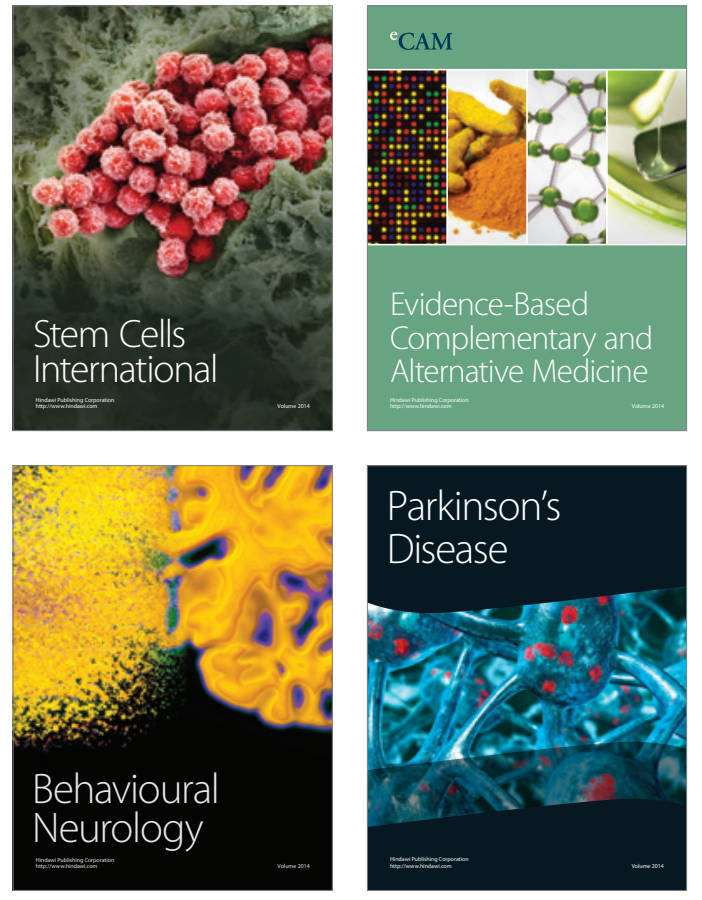
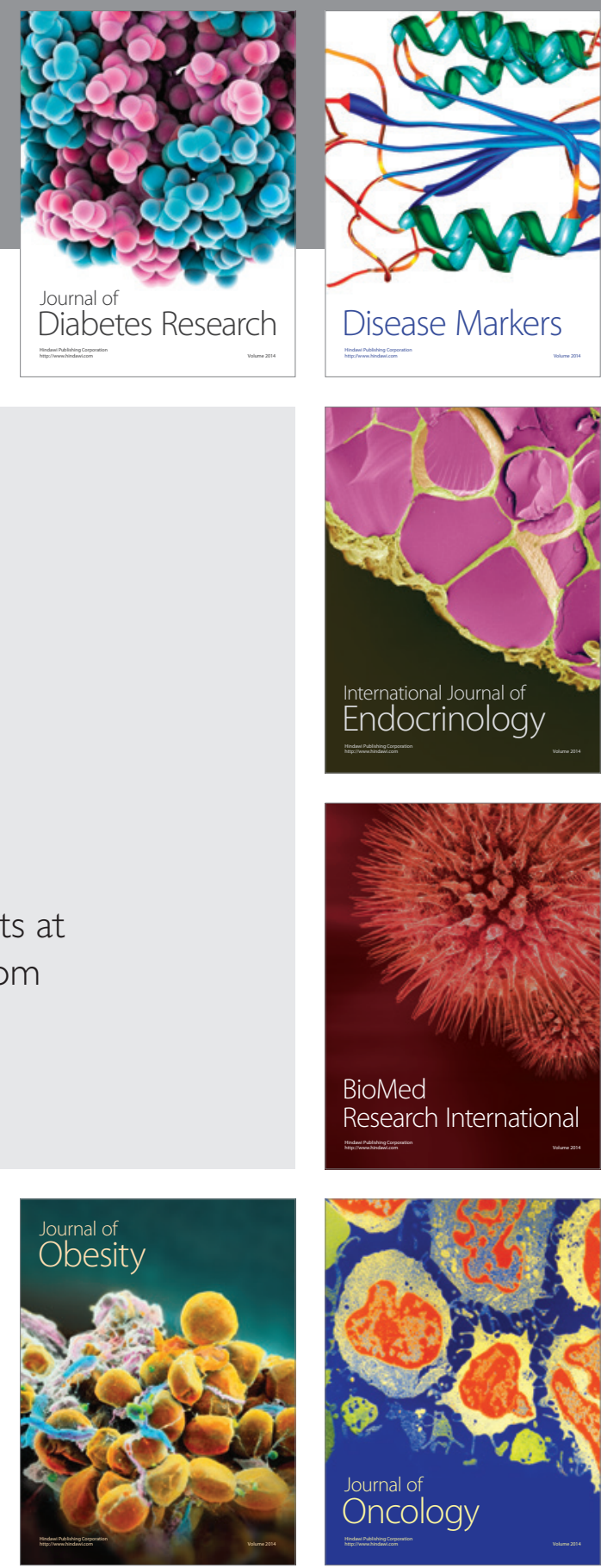

Disease Markers
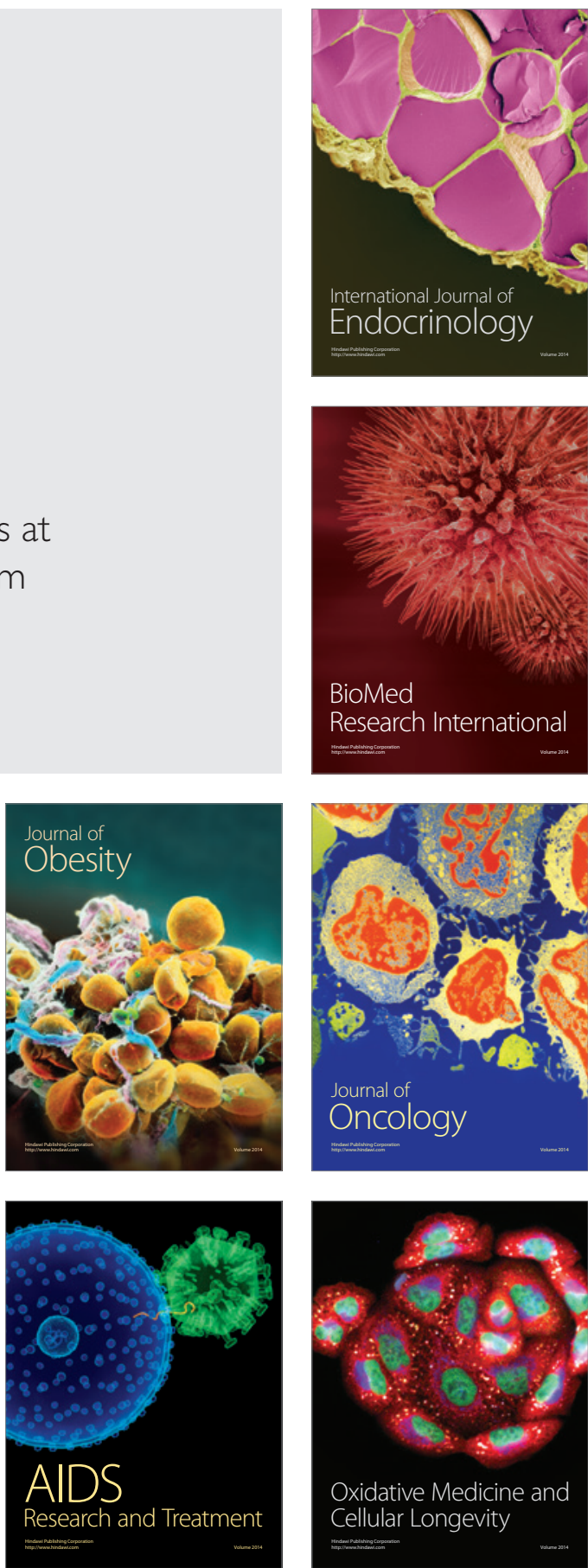